International Journal of
Agriculture
(IJA)

\title{
IMPACT OF THE INVASIVE CUSCUTA CAMPESTRIS ON VEGETATIVE COVER AND PLANT BIODIVERSITY IN HOMA- BAY COUNTY
}

Orwah Pamela Akoth, Prof J.B. Okeyo Owuor and Prof. D. Nyamai 
International Journal of Agriculture

ISSN 2520-4629X (Online)

Vol.6, Issue 1, No.3. pp. 39 - 45, 2021

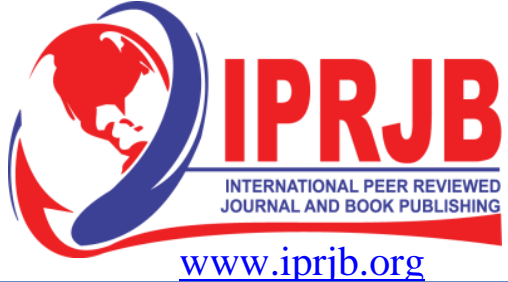

IMPACT OF THE INVASIVE CUSCUTA CAMPESTRIS ON VEGETATIVE COVER AND PLANT BIODIVERSITY IN HOMA- BAY COUNTY

\author{
Orwah Pamela Akoth \\ School of Agriculture, Natural Resources and Environmental Studies: Rongo University. \\ Prof J.B. Okeyo Owuor \\ School of Agriculture, Natural Resources and Environmental Studies: Rongo University \\ Prof. D. Nyamai \\ School of Agriculture, Natural Resources and Environmental Studies: Rongo University.
}

\begin{abstract}
Purpose: This research paper focused on the impact of Cuscuta campestris on vegetative cover and plant biodiversity in Homa-Bay County. The specific objective was to investigate the impact on plant growth and development with indicator as photosynthetic capacity of preferred host plants and chlorophyll content and leaf weight as the parameters.
\end{abstract}

Methodology: The study was conducted in hot-spot areas of invasion, Rachuonyo North, Homa Bay town and Suba North using Completely Randomized Experimental Block Design. The data was collected through field observation and laboratory analysis. The study used descriptive and correlation data analysis procedures to show the impact on photosynthetic capacity, ANOVA to determine statistical significant difference among the obtained results for each parameter of the infected and uninfected samples. Variance analysis were conducted using SPSS 20 (IBM Corp. Armonk, NY, USA) and differences between means tested by ANOVA. Values of $\mathrm{P} \leq 0.05$ were considered significantly different.

Findings: The results showed that the invasion was more intense in Theveta peruvinia and Euphorbia tirucalli species. Mean leaf amounts of chlorophyll were observed to decline with chlorophyll a from 3.97 to $1.59 \mathrm{mg} / \mathrm{g}$ and chlorophyll $\mathrm{b}$ from 2.65 to $1.18 \mathrm{mg} / \mathrm{g}$ and total chlorophyll value from 6.62 to $2.76 \mathrm{mg} / \mathrm{g}$ on infection resulting to reduced photosynthetic efficiency and low organic material formation. Leaf wet and dry weight significantly decreased in both infected varieties. The mean wet weight of $17.61 \mathrm{~g}$ in infected was significantly different, $\mathrm{F}(1,4)=235.74, \mathrm{p}<.05$, from the mean wet weight of $24.23 \mathrm{~g}$ in the uninfected Yellow Oleander while the mean dry weight of $5.55 \mathrm{~g}$ in infected was significantly different, $\mathrm{F}$ $(1,4)=159.72, \mathrm{p}<.05$, from mean dry weight of $7.87 \mathrm{~g}$ in uninfected Yellow Oleander. Similarly, significant difference, $\mathrm{F}(1,4)=714.64, \mathrm{p}<.05$, was observed in Calliandra calothyrsus variety. These demonstrated how $C$. campestris is detrimental causing ecological impacts with direct effects on plant biodiversity by reducing growth and development of infected host plant and even leading to death.

Unique Contributions to Theory, Practice and Policy: The paper recommends intense sensitization of the community on the impacts of dodder from the findings for an enhanced understanding and need for management and control. The findings to be disseminated through workshops involving farmers, NGOs and community based organisations, academic conferences and publications to help create awareness on the impacts and mobilize the entire public on management and possible total eradication. Further research to investigate on nutrients of attraction in the preferred host plants with an aim of permanent solution for total eradication in order to restore the vegetative cover and plant biodiversity.

Keywords: Cuscuta campestris, Thevetia peruviana, Euphorbia tirucalli, Calliandra calothyrsus, Impact, Chlorophyll content, Leaf mass, Vegetative cover and Plant Biodiversity 
International Journal of Agriculture

ISSN 2520-4629X (Online)

Vol.6, Issue 1, No.3. pp. 39 - 45, 2021

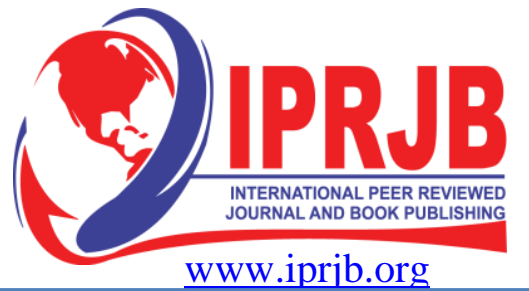

\section{INTRODUCTION}

\section{Background of the study}

Dodder is a parasitic vine, grows rapidly, entwining and parasitizing its host plants by inserting haustoria into the host plants' stem (Oroche, 2015). It is one of the most recent invasive parasitic plant in Homa -Bay County where it has been widely recorded on a range of field crops, pasture legumes, vegetables, horticultural crops, trees and many vegetative shrubs. It is mainly found along rivers, creeks, floodplains and irrigation areas. Invasive species often compete so successfully in new ecosystems that they displace native species and disrupt important ecosystem processes.

\section{Statement of the Problem}

C. Campestris invasion in Homa Bay County is at alarming rate and management and control has become almost impossible thus need adequate scientific understanding. The impact of invasion is not well understood due to lack of scientific data in Homa Bay County. Further, the impact on photosynthetic capacity, plant growth and development have not been investigated.

\section{Conceptual Framework}

The independent variable of this study was dodder invasion while dependent variables of the study were chlorophyll content level and leaf mass of the infected plants with output as impact on photosynthetic capacity and yield of the invaded plants.

\section{RESEARCH METHODOLOGY AND MATERIALS}

The study involved quantitative method for data collection procedures, analysis and interpretation. The study generated quantitative data through field and laboratory measurements, and observations. Data collection was done between July 2019 and December 2020. The study employed a survey and Completely Randomized Block Design in which quantitative data was obtained by field observations and measurements as well as laboratory analysis based on objective of the study. Homa Bay is located in the southern part of Winam Gulf, Lake Vitoria Basin. The county covers an area of $3,183.3 \mathrm{sq} \mathrm{km}$ with a population of about 963,794 people. It is located about $420 \mathrm{~km}$ from Nairobi. The target area for this study constituted the hot spot areas of invasion along the lake shores of Mbita of Suba North Sub County. The study used purposive sampling method where hot spot areas of invasion were selected within Suba North that constituted the study sites. Two samples, infected and uninfected were picked from each of the two identified common hosts from the two study sites making a total of 12 samples of leaves. The study relied on primary data collected directly from the study sites. The study employed a combination of two instruments to address the depth of the problem. These included laboratory experimental measurements and field observations based on objective. The study used descriptive and correlation data analysis procedures. ANOVA was done in order to determine whether there was a statistical significant difference among the obtained results for each parameter of the infected and uninfected samples. Variance analysis was carried out using SPSS 20 (IBM Corp. Armonk, NY, USA) and differences between means were tested by ANOVA. Values of $\mathrm{P} \leq 0.05$ were considered significantly different. The research used tables to present the analyzed data related to impact on photosynthetic capacity and yield to predict the impact on 
International Journal of Agriculture

ISSN 2520-4629X (Online)

Vol.6, Issue 1, No.3. pp. 39 - 45, 2021

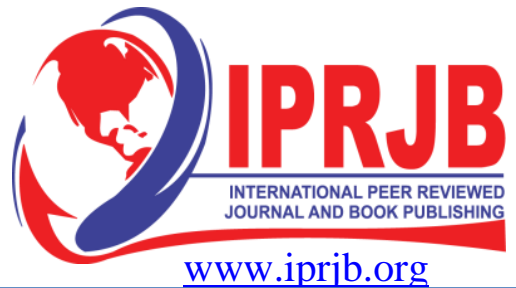

general plant growth and development. The quantitative data analysis then took descriptive statistics to summarize the data obtained for each objective.

\section{RESULTS AND DISCUSSION}

\section{Common Host trees and Shrubs}

The most preferred host plants by family were Fabaceae/Leguminoceae with 5 species parasitized followed by Apocynaceae and Euphorbiaceae family with a total of 3 species each and then other families as seen in table 1.0 below

Table 1.0: Host plant Species Identified by plant family

\begin{tabular}{|l|l|}
\hline Host Plant Family & No. of Species identified \\
\hline Salicaceae & 1 \\
\hline Apocynaceae & 3 \\
\hline Euphorbiaceae & 1 \\
\hline Myrtaceae & 2 \\
\hline Solanaceae & 1 \\
\hline Rubiaceae & 1 \\
\hline Convolvulanaceae & 5 \\
\hline Fabaceae & 1 \\
\hline Lauraceae & 2 \\
\hline Poaceae & 1 \\
\hline Rosaceae & 1 \\
\hline Cupressaceae & 1 \\
\hline Malvaceae & 1 \\
\hline Verbenaceae & \\
\hline
\end{tabular}

\section{Discussion}

From the table, dodder has a wide range of hosts. The most preferred host plants by family were Fabaceae/Leguminoceae with 5 species parasitized followed by Apocynaceae and Euphorbiaceae family with a total of 3 species each and then other families as seen in table 4.1 above. The graph showing the percentage distribution of host plants in the study sites was generated as seen in figure 1.0 below 


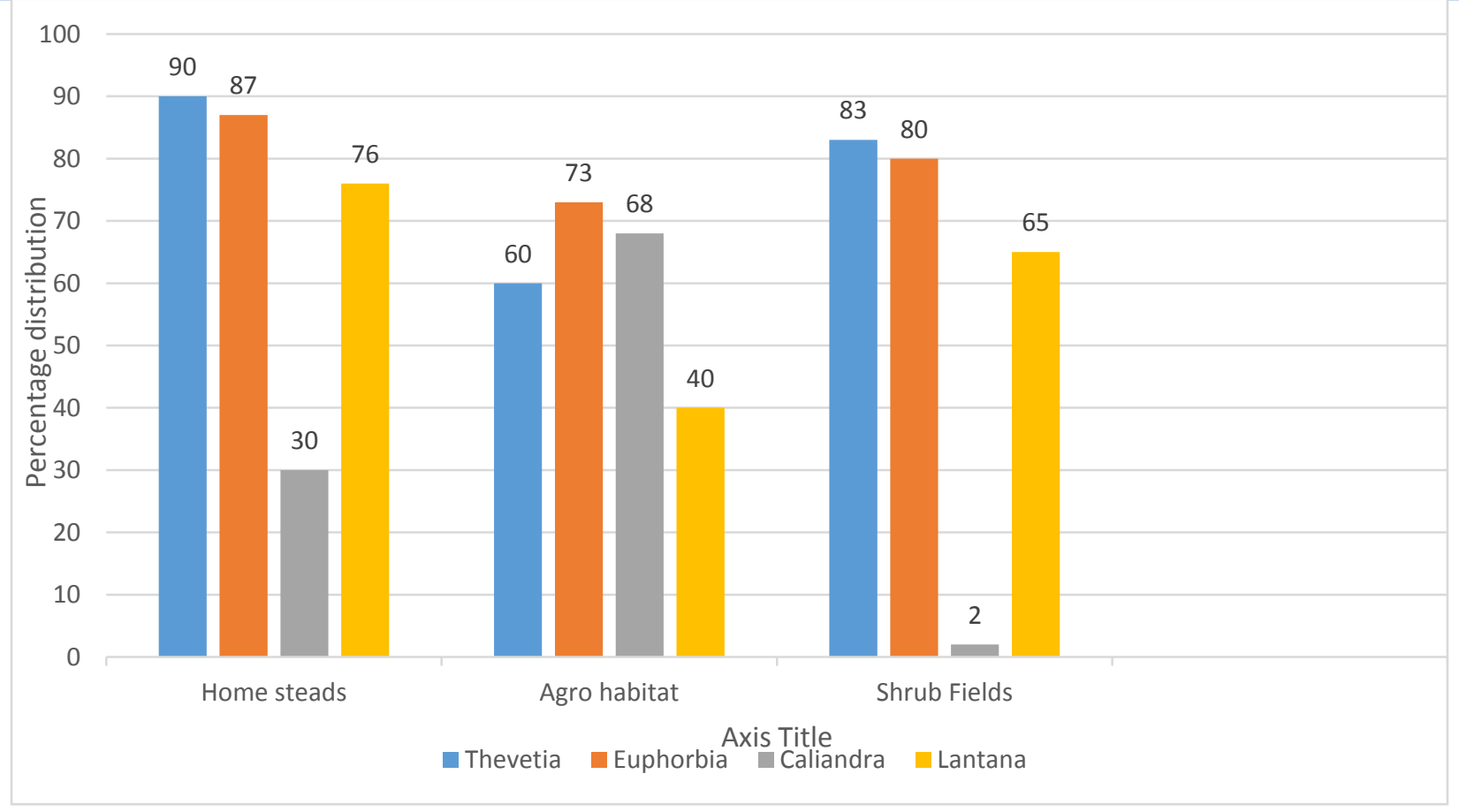

Figure 1.0: Graphical presentation of percentage host plants infected

\section{Discussion}

In homestead regions, Thevetia and Euphorbia plants are mostly infected since they are the mostly used live fence and their sappy nature that is preferred by dodder while in Agro habitat region, Caliandra is one of the most infected after Euphorbia since it is a fodder crop/tree. In Shrub fields, all the examined trees and shrubs were abundantly infected except for caliandra that were less frequent in the fields. These plant species were observed to have sappy leaves and stems and produces latex. This implies that the host plants commonly attacked by field dodder have sappy and latex characteristic which probably imply easy flow of nutrients as parasitic plant attaches its haustorium in order to get access and withdraw the required nutrients and minerals for its life-long subsistence.

\section{Impact of Cuscuta campestris on Photosynthetic Capacity of Host Plant}

The study sort to find dodder effect on chlorophyll content. The content of chlorophyll a, b and total chlorophyll were determined as earlier described in the methodology chapter three. The findings were as tabulated in table 2.0 below 
International Journal of Agriculture

ISSN 2520-4629X (Online)

Vol.6, Issue 1, No.3. pp. 39 - 45, 2021

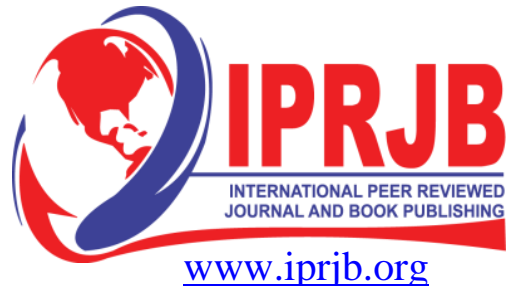

Table 2.0: Mean Chlorophyll content in Thevetia peruviana host plant

\begin{tabular}{lllll}
\hline $\begin{array}{l}\text { Chlorophyll } \\
\text { component }\end{array}$ & $\begin{array}{l}\text { Status of } \\
\text { Host Plant }\end{array}$ & $\begin{array}{l}\text { Mean Chlorophyll } \\
(\mathrm{mg} / \mathrm{g})\end{array}$ & $\begin{array}{l}\text { Standard } \\
\text { Deviation }\end{array}$ & \begin{tabular}{l} 
ANOVA \\
\hline Chlorophyll $a$
\end{tabular} \\
& Infected & 1.59 & .610 & $F(1,4)=29.73, p=.005$ \\
Chlorophyll b & Healthy & 3.97 & .448 & \\
& Infected & 1.18 & .698 & $F(1,4)=8.53, p=.043$ \\
& Healthy & 2.65 & .525 & \\
Total Chlorophyll & Infected & 2.76 & 1.306 & $F(1,4)=16.86, p=.015$ \\
& Healthy & 6.62 & .970 & \\
\hline
\end{tabular}

The table indicates that the mean amount of chlorophyll $a$ of $1.59 \mathrm{mg} / \mathrm{g}$ in infected host plants leaves was significantly different, $F(1,4)=29.73$, $\mathrm{p}<.05$, from the mean quantity of chlorophyll $a$ of $3.97 \mathrm{mg} / \mathrm{g}$ in the healthy host plant. Similarly, there was significant difference, $F(1,4)=$ $8.53, \mathrm{p}<.05$, between the mean amount of chlorophyll $b$ of $1.18 \mathrm{mg} / \mathrm{g}$ in infected leaves and 2.65 $\mathrm{mg} / \mathrm{g}$ in healthy leaves of host plants. Equally, as regard to total chlorophyll, there was significant difference, $F(1,4)=16.86, \mathrm{p}<.05$, between the mean amount of chlorophyll in infected leaves at $2.76 \mathrm{mg} / \mathrm{g}$ and for healthy leaves at $6.62 \mathrm{mg} / \mathrm{g}$. Therefore, the test of photosynthetic pigments in the leaves showed a significant difference $(\mathrm{P} \leq 0.05)$ in chlorophyll a and $b$ and total chlorophyll between the healthy and unhealthy samples. This meant that parasitic field dodder affects photosynthetic capacity of host plants by decreasing the amount of chlorophyll $a$ and $b$.

\section{Effect of Cuscuta campestris on leaf matter of Host Plant}

Table 3.0: Effects of Cuscuta campestris on Leaf weight of Host Plant

\begin{tabular}{llll}
\hline \multicolumn{3}{l}{ Host Plant } & \multicolumn{3}{c}{ Yield } & $\begin{array}{l}\text { Standard } \\
\text { Deviation }\end{array}$ & ANOVA \\
\hline Yellow Oleander Infected Wet weight 17.61 & .715 & $F(1,4)=235.74, p=.000$ \\
& Healthy Wet weight 24.23 & .215 & \\
Yellow Oleander Infected Dry Weight 5.55 & .120 & $F(1,4)=159.72, p=.000$ \\
& Healthy Dry Weight 7.87 & .296 & \\
C. calothyrsus & Infected Wet weight 17.28 & .306 & $F(1,4)=714.64, p=.000$ \\
& Healthy Wet weight 27.67 & .600 & \\
C. calothyrsus & Infected Dry Weight 6.49 & .303 & $F(1,4)=62.57, p=.001$ \\
& Healthy Dry Weight 9.39 & .558 & \\
\hline
\end{tabular}

The analysis of experimental data indicated that the mean wet weight of $17.61 \mathrm{~g}$ in infected Yellow Oleander was significantly different, $F(1,4)=235.74, \mathrm{p}<.05$, from the mean wet weight of $24.23 \mathrm{~g}$ in the healthy Yellow Oleander plant. The table also shows that there was significant difference, $F(1,4)=159.72$, $\mathrm{p}<.05$, between the mean dry weight of $5.55 \mathrm{~g}$ in infected Yellow Oleander and $7.87 \mathrm{~g}$ in healthy Yellow Oleander. In addition, there was significant difference, $F$ 
$(1,4)=714.64, \mathrm{p}<.05$, between the mean wet weight of 17.28g in infected Calliandra and 27.67 $\mathrm{g}$ in the healthy Calliandra. Moreover, the mean dry weights of $6.49 \mathrm{~g}$ for the infected Calliandra and $9.39 \mathrm{~g}$ for the healthy Calliandra, had statistical significant difference, $F(1,4)=$ $62.57, \mathrm{p}<.05$. The findings suggest that parasitic field dodder plant reduced the yield of Yellow Oleander and Calliandra leaf wet weight and dry weight.

In a related report by Y1lmaz and Kadioğlu (2009), mean wet and dry weight of leaf in infected and uninfected variety of sugar beet plants showed similar trend and to those of Çatal and Akınerdem (2013). Previous studies also demonstrate that dodder decreases photosynthetic capacity of the leaves lowering the leaf biomass.

\section{CONCLUSION AND RECOMMENDATIONS}

\section{Conclusion}

Cuscuta campestris affects photosynthetic capacity of infected host plants, causing significant reductions in chlorophyll content. It also affects a number of parameters such as leaf weight showing that these parameters may be considered sensitive indicators of the impact that field dodder has on its host plants. From this study, the conclusions are:

- Cascuta campestris has variety of host plants with preference on Thevetia peruviana and Euphorbia tirucali.

- C. campestris has significant impact on photosynthetic capacity of host plants and on the general plant growth and development.

- Finally, it imposes both ecological and physiological impacts on both native and exotic species and to the general vegetative cover and plant biodiversity

\section{Recommendations}

From the study results and conclusions, the study recommendations are:

- Residents of Homa Bay county to practice substitution of preferred dodder host plant species, Yellow Oleander and Euphorbia with hardly infected plants as a way of reducing dodder infection in the fields, farms and homesteads

- C. campestris has significant impact on photosynthetic capacity of host plants and on the general plant growth and development.

- There is inadequate public awareness on impact of dodder hence the lack of effective attempt in management and control of its spread.

\section{FURTHER RESEARCH}

- Analysis of the nutrient composition of preference in Thevetia and Euphorbia plants in Homa Bay County as compared to other hosts.

- The scientific body to conduct further research to establish workable control and management strategies of Cuscuta campestris in Homa Bay County based on the impacts. 


\section{ACKNOWLEDGEMENT}

This research paper has been developed with support from a number of individuals both within and without Rongo University. First, my gratitude goes to God Almighty, secondly to my supervisors, Prof J.B. Okeyo-Owuor and Prof D. Nyamai whose professional guidance has made this work a success. Thirdly, much appreciation to my family whose prayers and material support played a vital role in the development of this research paper. Blessings to all!

\section{REFERENCES}

1. ISSN 1021-4437, Russian Journal of Plant Physiology, 2018, Vol. 65, No. 5, pp. 726731. (C) Pleiades Publishing, Ltd., 2018.

2. Cunningham, Scott (2012). Cunninghams Encyclopedia of Margical Herbs. p. 149. ISBN 9780738717135.

3. Diego, R. (2011). Parasitic Plants. life sciences, 23, 654-676. doi: a 10.1002/9780470015902.a0021271

4. GoK. (2012). Plant Protection Order. Nairobi: Retrieved August 25, 2017.

5. Hassar, N. T, Dale, L. S, Scott, N., Phil, W., Baruch, R., (2009), Are Herbicide Resistant Crops the Answer to Controlling Cuscuta. Pest Management Science, 65(7): 811- 816 https://doi.org/10.1002/ps.1760. Retrieved March 18, 2019

6. Johnson, B. I., De Moraes, C. M. and Mescher, M. C. (2016), Manipulation of light spectral quality disrupts host location and attachment by parasitic plants in the genus Cuscuta. Journal of Applied Ecology, 53: 794-803. Retrieved May 18, 2017

7. Kerkhoff. (2010). Measuring biodiversity of ecological communities. Ecology Lab, 1-20.

8. Marambe, B. W. (2002). Growth and Development of Cuscuta chinensis Lam and its impact on selected crops. Weed Biology and Management, 2, 79-83. Retrieved october 20, 2016

9. Marija, S. a. (2015). Field Dodder-How to Control it. Pestic Phytomed, 30(3), 137-145. doi:10.2298/PIF1503137S 